\title{
4H-SiC Trench IGBT with Lower On-State Voltage Drop*
}

\author{
Yan-juan Liu ${ }^{a}$,Ying Wang ${ }^{a,{ }^{*}}$,Cheng-hao $\mathrm{Yu}^{b}, \mathrm{Fei}-\mathrm{Cao}{ }^{b}$ \\ a College of Information and communication Engineering, Harbin Engineering University, \\ 150001 Harbin, China \\ b Key Laboratory of RF Circuits and Systems, Ministry of Education, Hangzhou Dianzi \\ University, \\ 310018 Hangzhou, China.
}

\begin{abstract}
In this paper, a new $4 \mathrm{H}-\mathrm{SiC}$ trench-gate IGBT structure incorporated a $\mathrm{P}^{+}$shielding region in the emitter side is proposed in order to reduce the on-state voltage drop. Through the 2-D ATLAS simulation, the characteristics of the proposed structure are investigated and compared with the conventional structure. The simulation results indicate that the proposed structure exhibits an improvement in the following. Firstly, the on-state voltage drop is reduced by $32.75 \%$. Secondly, the differential specific on-resistance is reduced by $42.33 \%$. Finally, under the same on-state voltage drop, the turn-off energy is reduced more than $50.00 \%$. At the end of the paper, it is explored that what effects the physical parameter of the $\mathrm{P}^{+}$shielding region in the proposed structure have on the steady state performances.
\end{abstract}

Keyword: 4H-SiC, trench-gate IGBT, on-state voltage drop, trade-off curve.

\section{Introduction}

Due to the striking material properties of silicon carbide (e.g., about three times wider band gap of $3.26 \mathrm{eV}$, about ten times higher critical electrical field of $3 \mathrm{MV} / \mathrm{cm}$, about two times higher electron saturation drift velocity of $2.2 \times 10^{7} \mathrm{~cm} / \mathrm{s}$ and about three higher thermal conductivity than silicon

* Corresponding author.

E-mail address: wangying7711@yahoo.com (Y. Wang) 
material) [1], the SiC based semiconductor power devices such as MOSFET and IGBT are very promising devices for the high-power, high-frequency, and high-temperature applications. In recent years, 4H-SiC insulated gate bipolar transistors (IGBTs), especially for the > 10KV-class IGBTs, which are considered as the key components in some specific applications such as the smart grid system [2], high voltage boost converter and flexible AC transmission systems [3], have attracted considerable interests from the researchers owing to the ultra-low specific on-resistance compared with $4 \mathrm{H}-\mathrm{SiC}$ MOSFET [5-8].

The performance of IGBT has been greatly improved with the use of the field stop (FS) [9] and current enhancing layer (CEL) technology [3-4], especially for the trade-off between the on-state voltage drop and the turn-off loss. And the advent of the trench gate technology improves the characteristics of IGBT further [10]. Compared to the planar gate structure, the trench gate structure could increase the conductive channel density and eliminate the parasitic JFET effect. Thus a lower specific on-resistance and on-state voltage drop can be obtained and the trade-off between the on-state voltage drop and the turn-off loss could also be improved. However, the trench gate structure has a drawback that a crowding field occurs at the gate oxide corner of the trench-gate bottom [1, 11] and this will degrade the blocking performance. In order to solve the problem mentioned above, a heavy doping $\mathrm{P}^{+}$field shielding region is introduced under the bottom of the trench-gate [11], and it is especially important for the $4 \mathrm{H}-\mathrm{SiC}$ trench-gate devices. However, due to the introduction of the heavy doping $\mathrm{P}^{+}$shielding region, two parasitic JFET resistances will be introduced, which one is composed of the $\mathrm{P}$-base region and the heavy doping $\mathrm{P}^{+}$shielding region and the other one consists of the two close heavy doping $\mathrm{P}^{+}$shielding regions. This increases the specific on-resistance and on-state voltage drop enormously, and degrade the trade-off between the on-state voltage drop and the turn-off energy 
loss.

In past several years, some high-voltage 4H-SiC IGBTs with the breakdown voltage in range from 10 to $22 \mathrm{KV}$ have been reported [12-24]. However, these works mostly focus on planar gate $4 \mathrm{H}-\mathrm{SiC}$ IGBT and a few studies about $4 \mathrm{H}-\mathrm{SiC}$ trench IGBT $[12,15,22]$. And in this paper, a new $4 \mathrm{H}-\mathrm{SiC}$ n-channel trench-gate IGBT with an emitter heavy doping trench $\mathrm{P}^{+}$field shielding layer (hereafter called as E-P $\mathrm{P}^{+}$-TIGBT) is proposed for the purpose of reducing the on-state voltage drop. The proposed structure eliminates the parasitic JFET resistance in the electron-current flow direction and enhances the conductivity modulation in the $\mathrm{N}^{-}$drift region under the trench-gate, leading to the reduction of the on-state voltage drop and differential specific on-resistance. And through charge compensation principle, the $\mathrm{P}^{+}$shielding region under emitter can also prevent the gate oxide field from the high electric field. The electrical performances of the proposed structure is investigated through 2-D numerical simulation and is compared with the conventional $4 \mathrm{H}-\mathrm{SiC}$ trench-gate IGBT with the heavy doping $\mathrm{P}^{+}$shielding under trench-gate bottom (hereafter called as G-P $\mathrm{P}^{+}$-TIGBT). Furthermore, physical parameters of the $\mathrm{P}^{+}$shielding region in the E-P $\mathrm{P}^{+}$-TIGBT such as the thickness of the $\mathrm{P}^{+}$ shielding region $\left(\mathrm{T}_{\mathrm{P}+}\right)$ and the width of the $\mathrm{P}^{+}$shielding region $\left(\mathrm{W}_{\mathrm{P}+}\right)$ are varied to predict the proposed device characteristics.

\section{Device simulation setup}

Fig. 1(a) shows a simplified cross-sectional view of a half-cell of the proposed structure with an emitter heavy doping trench $\mathrm{P}^{+}$field shielding region (E-P $\mathrm{P}^{+}$-TIGBT). And a schematic diagram of the conventional trench structure (G-P $\mathrm{P}^{+}$TIGBT) is shown in Fig. 1(b), whose strucure is similar to [12]. The main differences between the proposed structure and the conventional structure are the existence of emitter trench and the location of $\mathrm{P}^{+}$shielding region. The two structures have the same cell 
dimensions for the comparison. The thickness of the side gate oxide is $50 \mathrm{~nm}$ and the bottom is $100 \mathrm{~nm}$, and the thickness of oxide in the emitter trench is also $50 \mathrm{~nm}$. The gate of the two structures is n-type poly-silicon. And in order to block the $15 \mathrm{KV}$, the doping and thickness of $\mathrm{N}$ - drift region is chosen based on [18] and [25]. The physical parameters of the every region are shown in TABLE I.

In this paper, ATLAS device simulator is utilized to explore the characteristics of the E-P ${ }^{+}$-TIGBT and the G-P ${ }^{+}$-TIGBT. The device simulation is carried out by the concentration and temperature dependent mobility (ANALYTIC), the field dependent mobility (FLDMOB), the carrier statistics models uses bandgap narrowing (BGN), Shockley-Read-Hall (SRH) and Auger recombination (AUGER). Moreover, Selberherr's impact ionization model is also utilized. And the material parameters [26] of $4 \mathrm{H}-\mathrm{SiC}$ used in the simulation are shown in TABLE II. And all simulations are carried out at the room temperature.

In addition, due to the wider band-gap and the lower intrinsic carrier concentration of the $\mathrm{SiC}$ material, the convergence problem easily occurs when the SiC based power devices are simulated. Thus the numerical precision of the simulator is taken into account. Fortunately, in order to support the simulation of the wide band-gap materials ( $\mathrm{SiC}$ and $\mathrm{GaN}$ ), ATLAS could now run at several levels of the extended precision as well [26]. By default, ATLAS uses a nominal arithmetic precision of 64 bits. And ATLAS also gives the nominal precision that should be required to simulate the common semiconductor materials at room temperature and the $4 \mathrm{H}-\mathrm{SiC}$ material needs a precision of 256 bits which is the maximum for ATLAS. But for well-converged solutions, the run-time increases with precision. Considering the run-time and the precision, a precision of 128 bits is utilized to simulate the IGBT based on the $4 \mathrm{H}-\mathrm{SiC}$ in the all simulations in our paper.

\section{Characterization and discussion}


In this section, the electrical performances of the E- $\mathrm{P}^{+}$-TIGBT and the G-P ${ }^{+}$-TIGBT are investigated and compared through the extensive simulation. And the electrical performances include the on-state characteristics, off-state characteristics and turn-off behavior under a clamped inductive load. In the end of this section, we investigate the effect of the physical parameters of the $\mathrm{P}^{+}$shielding in the E-P $\mathrm{P}^{+}$-TIGBT $\left(\mathrm{T}_{\mathrm{P}+}, \mathrm{W}_{\mathrm{P}+}\right)$ on the device's characteristics

A. The steady state characteristic

The simulated on-state I-V performance of the E-P ${ }^{+}-$TIGBT and the G-P ${ }^{+}-$TIGBT is shown in Fig. 2. The simulation results indicates that the E-P $\mathrm{P}^{+}$-TIGBT structure can obtain an on-state voltage drop of $9.12 \mathrm{~V}\left(@ V_{\mathrm{ge}}=20 \mathrm{~V}\right.$ and $I_{\mathrm{ce}}=100 \mathrm{~A} / \mathrm{cm}^{2}$ ), while the G-P - TIGBT has an on-state voltage drop of 13.56 $\mathrm{V}$ at the same conditions. The on-state voltage drop $V_{\text {ce-on }}$ is improved by $32.75 \%$. Fig. 3 shows the hole concentration distribution at $I_{\mathrm{ce}}=100 \mathrm{~A} / \mathrm{cm}^{2}$ and $V_{\mathrm{ce}}=9.12 \mathrm{~V}$ for E-P - TIGBT and $V_{\mathrm{ce}}=$ 13.56 $\mathrm{V}$ for $\mathrm{G}-\mathrm{P}^{+}$-TIGBT, demonstrating that the two structures have almost identical hole concentration. And then what results in the reduction of on-state voltage drop in E-P ${ }^{+}$-TIGBT. The main factor responsible for this is due to the reduction of the resistance on the current flow path. The on-state voltage drop equals to a drop in the voltage generated by the resistance of the current flow from the emitter electrode to the collector electrode during the on-state. The E-P ${ }^{+}$TIGBT eliminates the parasitic JFET effect formed between the P-body and $\mathrm{P}^{+}$shielding regions, which exists in G-P ${ }^{+}$-TIGBT, leading to a large reduction in resistance. Because of the smaller resistance, a lower voltage drop is obtained when flowing the same level current. In addition, the factor, responsible for the hole concentration difference shown in the Fig. 3 (b), is due to the difference of the depletion layer location (shown in Fig. 4).

In addition, through the calculation based on the I-V curves, the differential specific on-resistance of 
the E-P - TIGBT and the G-P -TIGBT is 38.03 and $65.94 \mathrm{~m} \Omega \cdot \mathrm{cm}^{2}$ under the point of the $I_{\mathrm{ce}}=100$ $\mathrm{A} / \mathrm{cm}^{2}$ and $V_{\mathrm{ge}}=20 \mathrm{~V}$, respectively. The main factor responsible for this is due to the introduction of the $\mathrm{P}^{+}$shielding region in the emitter eliminating the parasitic JFET resistance in the electron current flow direction, which is composed of the p-base region and the $\mathrm{P}^{+}$shielding region under the trench-gate bottom in the G-P'-TIGBT. Fig. 4 shows the edge of the depletion region (shown by black line) under the forward conduction in these two structures, clearly indicating that the $\mathrm{P}^{+}$field shielding region can effectively reduce on-resistance in the electron current flow direction, especially the parasitic JFET

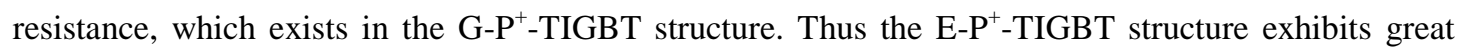
improvement in the differential specific on-resistance compared to the G-P - -TIGBT structure.

The off-state characteristic is also investigated. Fig. 5 presents the electric field distribution of upper section of the two structures at avalanche breakdown, where the collector electrode is biased at 15000 $\mathrm{V}$ for the E-P $\mathrm{P}^{+}$-TIGBT and the G-P $\mathrm{P}^{+}$-TIGBT. When the avalanche breakdown occurs, the maximum electric field in $4 \mathrm{H}-\mathrm{SiC}$ and in oxide is 3.6 and $2.2 \mathrm{MV} / \mathrm{cm}$ in the E-P $\mathrm{P}^{+}$-TIGBT, whereas in the G-P $\mathrm{P}^{+}$-TIGBT it is 3.4 and $2.7 \mathrm{MV} / \mathrm{cm}$. In this paper, we assume that the critical electric field in $4 \mathrm{H}-\mathrm{SiC}$ and in silicon dioxide is 3.0 and $4.0 \mathrm{MV} / \mathrm{cm}$. Thus, the E-P $\mathrm{P}^{+}$TIGBT and the G-P $\mathrm{P}^{+}$-TIGBT have the almost identical blocking capability.

B. Turn-off behavior under clamped inductive load

The high-voltage 4H-SiC IGBTs are promising candidate for the application used as a switching device. As a switching device, it is important to investigate its turn-off behavior under a clamped inductive load [13-14]. In this paper, mixed circuit and device simulator is used to explore the device's transient performance. In our simulation, a constant current source is applied to model the inductive load and the bus voltage is $9000 \mathrm{~V}$ ( $60 \%$ of the breakdown voltage). The gate resistor is $10 \Omega$ and the 
gate voltage changes from $20 \mathrm{~V}$ to $-5 \mathrm{~V}$, whose frequency is $5 \mathrm{KHz}$ with a $50 \%$ duty cycle, to control the device's turn-on and turn-off and the diode is an ideal element. The test circuit for the switching simulation under clamped inductive load is shown in Fig. 6. The constant current source is selected to 2.1 A, and the device's area is $0.021 \mathrm{~cm}^{2}$, making the current density following the device be 100 $\mathrm{A} / \mathrm{cm}^{2}$.

The simulated turn-off behavior under clamped inductive load is presented in Fig. 7. From this figure, it can be seen that the simulated curves of the switching behavior are almost overlapping, which demonstrates the turn-off time and turn-off energy loss is identical. The main factor causing this is that the enhanced conductivity modulation exists in the upper part of the $\mathrm{N}$ - drift region and is away from the collector electrode. The extensive holes, which are caused by the enhanced conductivity modulation, are swept out to the emitter electrode through the $\mathrm{P}^{+}$shielding region. And as for the electrons caused by the enhanced conductivity modulation are cleared away by the recombination with the holes in the $\mathrm{N}$-drift region. So the turn-off performance of the proposed structure is not degraded when compared with the conventional structure.

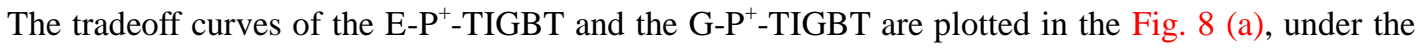
condition of the $I_{\mathrm{ce}}=100 \mathrm{~A} / \mathrm{cm}^{2}$ and $V_{\mathrm{ge}}=20 \mathrm{~V}$. The every point is obtained by changing the carrier lifetime in the $\mathrm{N}$ - drift region, and the carrier lifetime is 5, 1, 0.7 and $0.4 \mu$ s for E-P+-TIGBT and 100, 40,5 , and $1 \mu \mathrm{s}$ for G-P+-TIGBT, respectively. It can be seen from this graph that the turn-off energy is reduced more than $50.00 \%$ under the same $V_{\text {ce,on }}$. In order to verify this, the hole concentration distribution is shown in Fig. 8 (b) when the two structures have the same current and the same voltage. Form this figure, it can be seen the two factors responsible for the lower switching loss in E-P $\mathrm{P}^{+}$-TIGBT when has the same on-state voltage drop with G-P ${ }^{+}$-TIGBT. One is due to the lower 


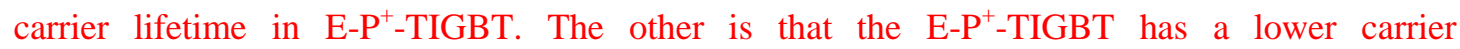
concentration stored in the $\mathrm{N}$ - drift region, which need to remove during the turn-off state.

\section{Parameter optimization}

In this section, it will be investigated what the physical parameters of the $\mathrm{P}^{+}$shielding in the E-P $\mathrm{P}^{+}$-TIGBT have effect on the steady state performances, mainly including the thickness of the $\mathrm{P}^{+}$ shielding $T_{\mathrm{P}+}$ and the width of $\mathrm{P}^{+}$shielding $W_{\mathrm{P}+}$. The maximum electric field in silicon carbide and silicon dioxide and the on-state voltage drop is used to depict the off-state and on-state performances.

Fig. 9 shows the relationship between the thickness of the $\mathrm{P}^{+}$shielding and the steady state performance. It is seen that the thickness of the $\mathrm{P}^{+}$shielding has minor influence on the maximum electric field in the silicon carbide, but major influence on the maximum electric field in the silicon dioxide and the on-state voltage drop. With the increasing of the thickness of the $\mathrm{P}^{+}$shielding, the depletion between $\mathrm{P}^{+}$shielding and $\mathrm{N}$-drift regions is bigger and the path for current flow is smaller, leading to the increase of the resistance in the electron current flow direction and the increase of the on-state voltage drop. The effect of the electric field shielding in silicon dioxide becomes strong and the maximum electric field in silicon carbide is small with the increase of the thickness of the $\mathrm{P}^{+}$ shielding. In addition, the influence of the width of the $\mathrm{P}^{+}$shielding on the steady state performances is shown in Fig. 10. And the width of the trench emitter is equal to the width of the $\mathrm{P}^{+}$shielding region in all simulations. Compared to Fig. 9, the width of the $\mathrm{P}^{+}$shielding has minor influence on the maximum electric field, whereas has greater effect on the on-state voltage drop. When the width of the $\mathrm{P}^{+}$ shielding is changed from 0.6 to $1.0 \mu \mathrm{m}$, the maximum electric field is changed from 3.90 to 2.90 $\mathrm{MV} / \mathrm{cm}$ and from 2.25 to $2.2 \mathrm{MV} / \mathrm{cm}$ for $\mathrm{SiO}_{2}$ and $\mathrm{SiC}$, respectively. However, the on-state voltage drop changes from 8.73 to $11.03 \mathrm{~V}$. And the reason causing the increase of on-state voltage drop is the 
same with the thickness of the $\mathrm{P}^{+}$shielding.

\section{Conclusions}

In this paper, a new $4 \mathrm{H}-\mathrm{SiC}$ trench IGBT with a $\mathrm{P}^{+}$shielding region under the emitter $\left(\mathrm{E}-\mathrm{P}^{+}-\mathrm{TIGBT}\right)$ is proposed in order to reduce the on-state voltage drop, and is compared with the conventional $4 \mathrm{H}-\mathrm{SiC}$ trench IGBT with a $\mathrm{P}^{+}$shielding region under the trench gate bottom $\left(\mathrm{G}-\mathrm{P}^{+}\right.$-TIGBT) using a $2 \mathrm{D}$ finite element simulator-ATLAS. Through the simulation investigation, the E-P ${ }^{+}$-TIGBT structure exhibits much better on-state performances and the differential specific on-resistance, which the former is improved by 32.75\% (@ $V_{\mathrm{ge}}=20 \mathrm{~V}$ and $\left.I_{\mathrm{ce}}=100 \mathrm{~A} / \mathrm{cm}^{2}\right)$ and the latter is reduced by $42.33 \%$ at $T_{\mathrm{P}+}=$ $0.2 \mu \mathrm{m}, W_{\mathrm{P}+}=0.7 \mu \mathrm{m}$ and $N_{\mathrm{P}+}=1 \times 10^{18} \mathrm{~cm}^{-3}$, without degrading the off-state behavior. Moreover, the trade-off curve between the on-state voltage drop and turnoff energy loss is also explored. And the results exhibits that the turnoff energy loss is reduced more than $50.00 \%$ at the same on-state voltage drop. In addition, the width of the $\mathrm{P}^{+}$shielding region has minor effect on the maximum electric field and major effect on the on-state voltage drop. And the influence of the thickness of the $\mathrm{P}^{+}$shielding region on the maximum electric field in $\mathrm{SiC}$ is minor, but major on the maximum electric field in $\mathrm{SiO}_{2}$ and the on-state voltage drop.

\section{Acknowledgements}

This work was supported by the Excellent Youth Foundation of Heilongjiang Province of China (No. JC2015017) and the National Science Foundation of China (No.51371063),.

\section{Reference}

[1] B. Jayant Baliga, Silicon Carbide Power Device, World Scientific Publishing Co. Ltd, 2005. 
[2] J. W. Palmour, J. Q. Zhang, M. K. Das, R. Callanan, A. K. Agarwal and D. E. Grider, SiC Power Devices for Smart Grid Systems, 2010 international Power Electronics Conference (IPEC). (2010) 1006-1013.

[3] M. Östling, R. Ghandi, C. M. Zetterling, SiC power devices - present status, applications and future perspective, Power Semiconductor Devices and ICs (ISPSD).(2011) 10-15.

[4] M. Mori, K. Oyama, T. Arai, J. Sakano, Y. Nishimura, K. Masuda, K. Saito, Y. Uchino and H. Homma, A planar gate high-conductivity IGBT (HiGT) with hole barrier layer, IEEE trans. Electron Device. 54 (6) (2007) 1515-1520.

[5] Y. Sui, J. A. Cooper and X. Wang, Design, simulation, and characterization of high-voltage SiC p-IGBT, Proc. ICSCRM. (2007) 14-19.

[6] A. Saha and J. A. Cooper, A 1-KV 4H-SiC power DMOSFET optimized for low on-resistance, IEEE trans. Electron Device. 54 (10) (2007) 2786-2791.

[7] Y. Sui, X. Wang and J. A. Cooper, High-voltage self-aligned p-channel DMOS-IGBTs in 4H-SiC, IEEE Electron Device lett. 28 (8) (2007) 728-730.

[8] Y. Sui, G. G. Walden, X. Wang and J. A. Cooper, Device options and design considerations for high-voltage (10-20KV) SiC power switching devices, Mater. Sci. Forum. 527-529 (2006) $1449-1452$.

[9] T. Laska, M. Munzer, F. Pfirsch, C. Schaeffer, T. Schmidt, The Field Stop IGBT (FS IGBT). A new power device concept with a great improvement potential, Power Semiconductor Devices and ICs. (2000) 355-358. 
[10]F. Udrea, G. A. J. Amaratunga, Theoretical and Numerical Comparison between DMOS and Trench Technologies for Insulated Gate Bipolar Transistors, IEEE trans. Electron Device. 42 (7) (1995) 1356-1366.

[11]B. J. Baliga, Silicon Carbide Switching Device with Rectifying Gate, U.S. Patent 5396085. March 7, 1995.

[12] Q. Zhang, H-R. Chang, M. Gomez, C. Bui, E. Hanna, J. A. Higgins, T. Isaacs-Smith and J. R. Williams, 10KV Trench IGBTs on 4H-SiC, Power Semiconductor Devices and ICs. (2005) 303-306.

[13] Tomohiro Tamaki, Ginger G. Walden, Yang Sui and James A. Cooper, Numerical Study of the Turnoff Behavior of High-Voltage 4H-SiC IGBTs, IEEE trans. Electron Device. 55 (8) (2008) 1928-1933.

[14] Masataka Miyake, Masaya Ueno, Uwe Feldmann and Hans Jürgen Mattausch, Modeling of SiC IGBT Turn-Off Behavior Valid for Over 5-KV Circuit Simulation, IEEE trans. Electron Device. 60 (2) (2013) 622-629.

[15] K. G. Menon and E. M. S. Narayanan, Numerical Evaluation of 10-KV Clustered Insulated Gate Bipolar Transistor in 4H-SiC, IEEE trans. Electron Device. 60 (1) (2013) 366-373.

[16] Xiaokun Wang and James A. Cooper, High-Voltage n-Channel IGBTs on Free-Standing 4H-SiC Epilayers, IEEE trans. Electron Device. 57 (2) (2010) 511-515.

[17] Tomohiro Tamaki, Ginger G. Walden, Yang Sui and James A. Cooper, Optimization of ON-State and Switching Performances for 15-20 KV 4H-SiC IGBTs, IEEE trans. Electron Device. 55 (8) (2008) 1920-1927. 
[18] Sung, W., Wang, J., Huang, A. Q., and Baliga, B. J. Design and investigation of frequency capability of 15KV 4H-SiC IGBT, Power Semiconductor Devices \& IC's. (2009) 271-274.

[19] A. Kadavelugu, S. Bhattacharya, S. H. Ryu, E. Van Brunt, D. Grider, A. Agarwal, S. Leslie, Characterization of $15 \mathrm{KV}$ SiC n-IGBT and its Application Considerations for High Power Converters, Energy Conversion Congress and Exposition (ECCE). (2013) 2528-2535.

[20] Muhammad Usman and Muhammad Nawaz, Device design assessment of 4H-SiC n-IGBT - A simulation study, Solid-State Electronics. 92 (2014) 5-11.

[21] Nawaz, Muhammad, and F. Chimento, On the Assessment of Temperature Dependence of 10 - 20 kV 4H-SiC IGBTs Using TCAD, Materials Science Forum. 740-742 (2013) 1085-1088.

[22] Yonezawa, Yoshiyuki, et al, Device Performance and Switching Characteristics of $16 \mathrm{kV}$ Ultrahigh-Voltage SiC Flip-Type n-Channel IE-IGBTs, Materials Science Forum. 821-823 (2015) 842-846.

[23] K. G. Menon, L. Ngwendson, Akira Nakajima, E. M. Sankara Narayanan and Graham P. Bruce, Ultra high performance of $12 \mathrm{kV}$ Clustered Insulated Gate Bipolar Transistor (CIGBT) in 4H-SiC, Materials Science Forum. 717-720 (2012) 1139-1142.

[24] S. Ryu, C. Capell, C. Jonas, M. O’Loughlin, J. Clayton, E. Van Brunt, K. Lam, J. Richmond, A. Kadavelugu, S. Bhattacharya, A. Burk, A. Agarwal, D. Grider, S. Allen and J. Palmour, 20 kV 4H-SiC N-IGBTs, Materials Science Forum. 778-780 (2014) 1030-1033.

[25] Ryu, S., Capell, C., Van Brunt, E., Jonas, C., O’Loughlin, M., and Clayton, J., et al, Ultra high voltage MOS controlled 4H-SiC power switching devices, Semiconductor Science \& Technology. 30 (8) (2015) 084001-1 084001-7.

[26] ATLAS Device Simulation Software, Silvaco, Version 5.19.20R, 2012. 
Table captions:

TABLE I Physical parameters for the simulations

TABLE II Material parameters of $4 \mathrm{H}-\mathrm{SiC}$ 


\section{Figure captions:}

Fig. 1 Cross-sectional schematic of a half-cell (a) the proposed structure (b) the conventional structure

Fig. $2 I_{\text {ce }}-V_{\text {ce }}$ performance of E-P ${ }^{+}$-TIGBT and G-P ${ }^{+}$-TIGBT

Fig. 3 The hole concentration distribution along (a) $\mathrm{X}=1.8 \mu \mathrm{m}$ for $\mathrm{E}-\mathrm{P}^{+}$-TIGBT and $\mathrm{X}=0.0 \mu \mathrm{m}$ for

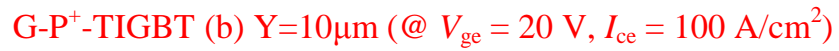

Fig. 4 The depletion edge in (a) E-P ${ }^{+}$-TIGBT (b) G-P ${ }^{+}$-TIGBT

Fig. 5 The electric field distribution of (a) E-P ${ }^{+}$-TIGBT (b) G-P ${ }^{+}$-TIGBT ( @ $V_{\text {ce }}=15000$ V)

Fig. 6 The simulation circuit for switching behavior under the clamped inductive load

Fig. 7 The comparison of the turn-off performance in two structures

Fig. 8 (a) The tradeoff curves of the two structures (b) hole concentration distribution at $\mathrm{X}=1.8 \mu \mathrm{m}$ for E-P $\mathrm{P}^{+}$-TIGBT (point A) and $\mathrm{X}=0.0 \mu \mathrm{m}$ for $\mathrm{G}-\mathrm{P}^{+}$-TIGBT (point B)

Fig. 9 The effect of the thickness of the $\mathrm{P}^{+}$shielding region on the electric field (@ $V_{\mathrm{ce}}=15000 \mathrm{~V}$ ) and on-state voltage drop $\left(@ I_{\mathrm{ce}}=100 \mathrm{~A} / \mathrm{cm}^{2}, V_{\mathrm{ge}}=20 \mathrm{~V}\right)$

Fig. 10 The effect of the width of the $\mathrm{P}^{+}$shielding region on the electric field (@ $V_{\mathrm{ce}}=15000 \mathrm{~V}$ ) and on-state voltage drop (@ $I_{\mathrm{ce}}=100 \mathrm{~A} / \mathrm{cm}^{2}, V_{\mathrm{ge}}=20 \mathrm{~V}$ ) 
TABLE I

Physical parameters for the simulations

\begin{tabular}{|c|c|}
\hline Parameter & Value \\
\hline Concentration of $\mathrm{P}^{+}$region & $1.0 \times 10^{20} \mathrm{~cm}^{-3}$ \\
\hline Thickness of $\mathrm{P}^{+}$region & $0.5 \mu \mathrm{m}$ \\
\hline Concentration of $\mathrm{N}^{+}$region & $1.0 \times 10^{20} \mathrm{~cm}^{-3}$ \\
\hline Depth of P-poly & $5.0 \mu \mathrm{m}$ \\
\hline Concentration of P-poly & $1.0 \times 10^{19} \mathrm{~cm}^{-3}$ \\
\hline Concentration of $\mathrm{N}$-drift & $4.5 \times 10^{14} \mathrm{~cm}^{-3}$ \\
\hline Concentration of $\mathrm{N}^{+}$buffer & $5.0 \times 10^{16} \mathrm{~cm}^{-3}$ \\
\hline Concentration of $\mathrm{P}^{+}$collector & $1.0 \times 10^{19} \mathrm{~cm}^{-3}$ \\
\hline Concentration of CEL & $1.0 \times 10^{16} \mathrm{~cm}^{-3}$ \\
\hline Thickness of CEL & $0.5 \mu \mathrm{m}$ \\
\hline Thickness of $\mathrm{P}^{+}$shielding in E- $\mathrm{P}^{+}$-TIGBT $\left(\mathrm{T}_{\mathrm{P}+}\right)$ & $0.2 \mu \mathrm{m}$ \\
\hline Concentration of $\mathrm{P}^{+}$shielding in E-P $\mathrm{P}^{+}$-TIGBT $\left(\mathrm{N}_{\mathrm{P}+}\right)$ & $1.0 \times 10^{18} \mathrm{~cm}^{-3}$ \\
\hline Width of $\mathrm{P}^{+}$shielding in in E-P $\mathrm{P}^{+}$-TIGBT $\left(\mathrm{W}_{\mathrm{P}+}\right)$ & $0.7 \mu \mathrm{m}$ \\
\hline Concentration of $\mathrm{P}^{+}$shielding in $\mathrm{G}^{-} \mathrm{P}^{+}$-TIGBT & $1.0 \times 10^{19} \mathrm{~cm}^{-3}$ \\
\hline Thickness of $\mathrm{P}^{+}$shielding in G-P ${ }^{+}$-TIGBT & $0.2 \mu \mathrm{m}$ \\
\hline Width of $\mathrm{P}^{+}$shielding in $\mathrm{G}^{-\mathrm{P}^{+}}$-TIGBT & $0.6 \mu \mathrm{m}$ \\
\hline
\end{tabular}


TABLE II

Material parameters of $4 \mathrm{H}-\mathrm{SiC}$

\begin{tabular}{|c|c|c|}
\hline $\begin{array}{l}\text { Material } \\
\text { Parameters }\end{array}$ & Value & Meaning \\
\hline Eg300 & $3.26 \mathrm{eV}$ & $\begin{array}{l}\text { the value of band-gap of } \\
\text { the material at } 300 \mathrm{~K}\end{array}$ \\
\hline Permittivity & 9.66 & $\begin{array}{l}\text { dielectric permittivity of } \\
\text { the material }\end{array}$ \\
\hline $\mathrm{E}_{\mathrm{db}}$ & $0.1 \mathrm{eV}$ & donor energy level \\
\hline $\mathrm{G}_{\mathrm{cb}}$ & 2 & $\begin{array}{l}\text { the conduction-band } \\
\text { degeneracy factor }\end{array}$ \\
\hline $\mathrm{E}_{\mathrm{ab}}$ & $0.2 \mathrm{eV}$ & acceptor energy level \\
\hline $\mathrm{G}_{\mathrm{vb}}$ & 4 & $\begin{array}{l}\text { the valence-band } \\
\text { degeneracy factor }\end{array}$ \\
\hline Taun0 & $1.0 \mu \mathrm{s}$ & SRH lifetime for electrons \\
\hline Taup0 & $1.0 \mu \mathrm{s}$ & SRH lifetime for holes \\
\hline Nsrhn & $3 \times 10^{17} \mathrm{~cm}^{-3}$ & $\begin{array}{l}\text { the SRH concentration } \\
\text { parameter for electron }\end{array}$ \\
\hline Nsrhp & $3 \times 10^{17} \mathrm{~cm}^{-3}$ & $\begin{array}{l}\text { the SRH concentration } \\
\text { parameter for holes }\end{array}$ \\
\hline
\end{tabular}




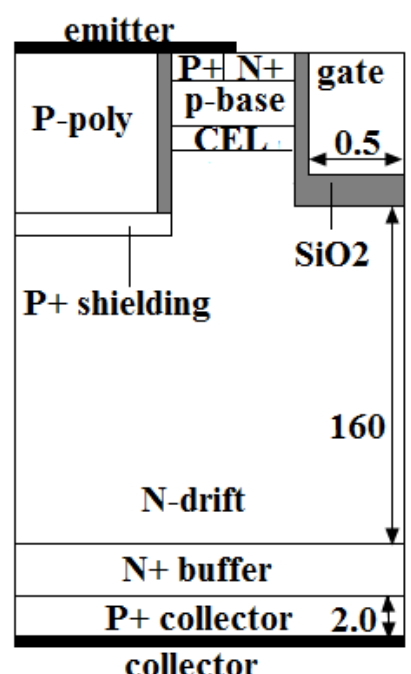

(a)

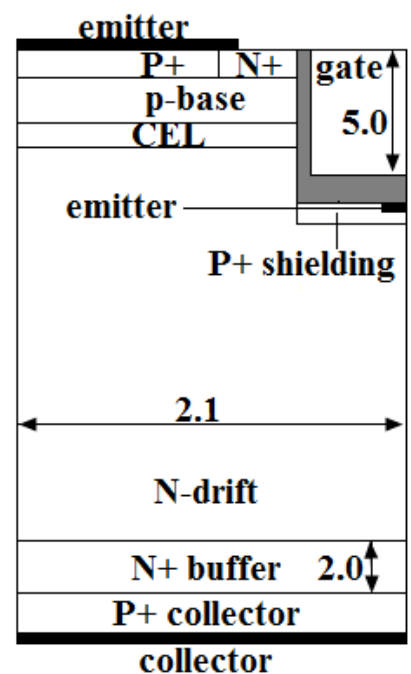

(b)

Fig. 1 Cross-sectional schematic of a half-cell (a) the proposed structure (b) the conventional structure 


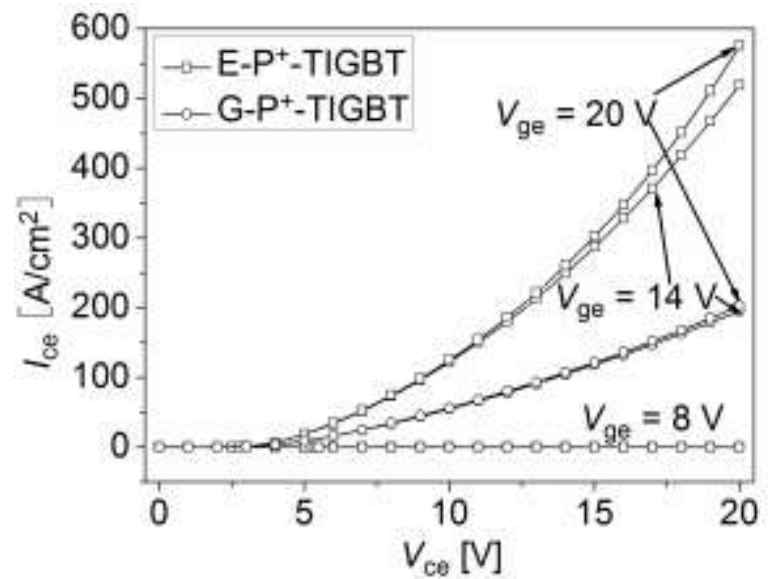

Fig. $2 I_{\mathrm{ce}}-V_{\mathrm{ce}}$ performance of E-P $\mathrm{P}^{+}$TIGBT and G-P $\mathrm{P}^{+}$TIGBT 


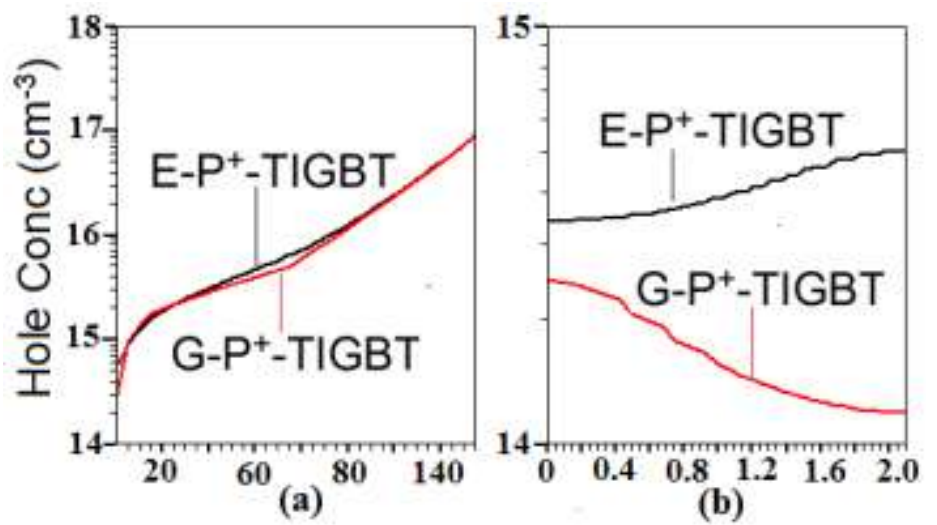

Fig. 3 The hole concentration distribution along (a) $\mathrm{X}=1.8 \mu \mathrm{m}$ for $\mathrm{E}-\mathrm{P}^{+}-\mathrm{TIGBT}$ and $\mathrm{X}=0.0 \mu \mathrm{m}$ for G-P ${ }^{+}$-TIGBT (b) Y=10 $\mu \mathrm{m}\left(@ V_{\mathrm{ge}}=20 \mathrm{~V}, I_{\mathrm{ce}}=100 \mathrm{~A} / \mathrm{cm}^{2}\right)$ 


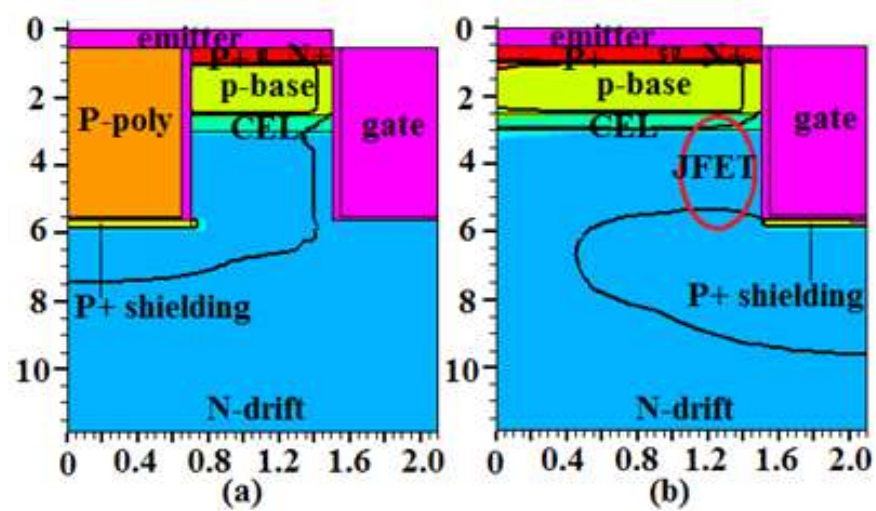

Fig. 4 The depletion edge in (a) E-P ${ }^{+}$-TIGBT (b) G-P ${ }^{+}$-TIGBT 


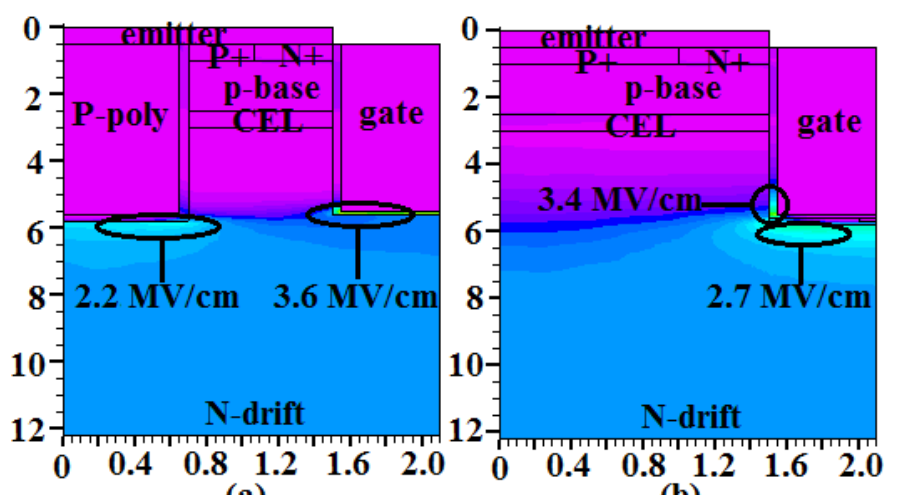

(a)

(b)

Fig. 5 The electric field distribution of (a) E-P -TIGBT (b) G-P+TIGBT (@ $V_{\text {ce }}=15000$ V) 


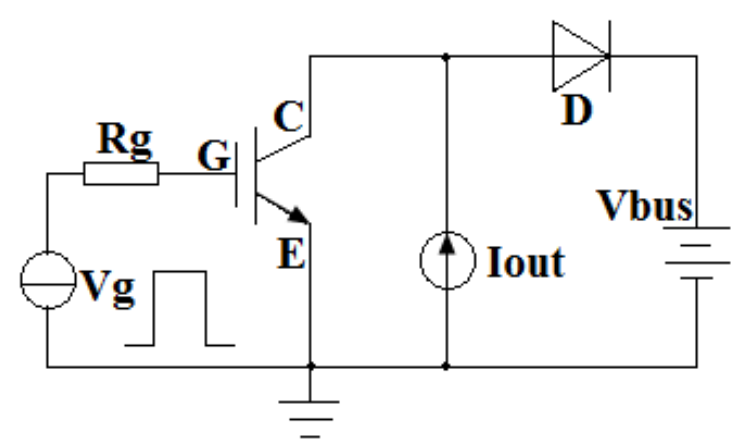

Fig. 6 The simulation circuit for switching behavior under the clamped inductive load 


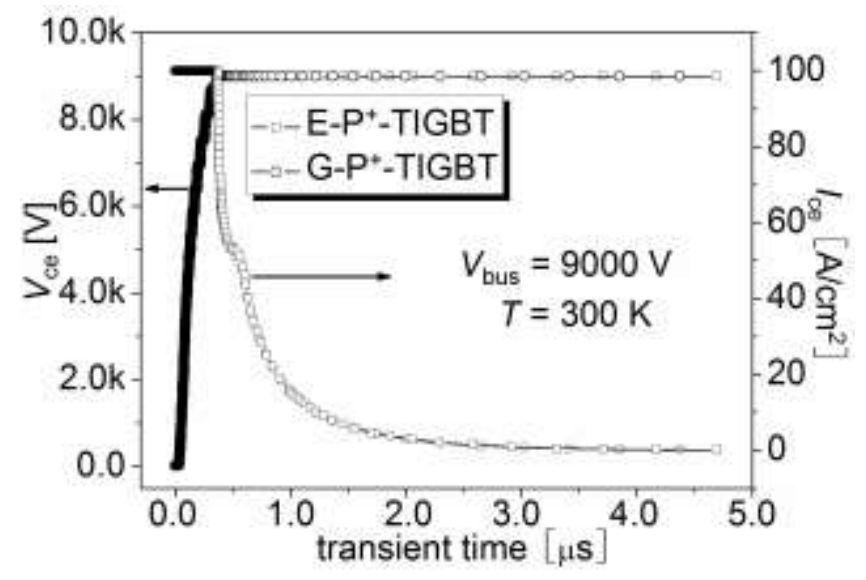

Fig. 7 The comparison of the turn-off performance in two structures 


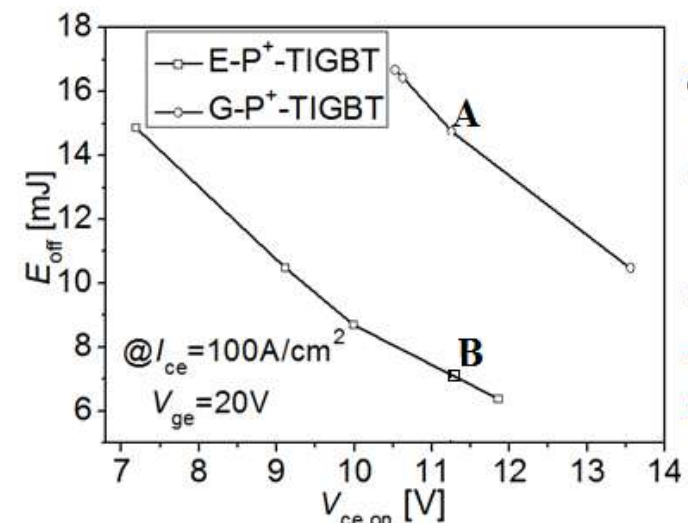

(a)

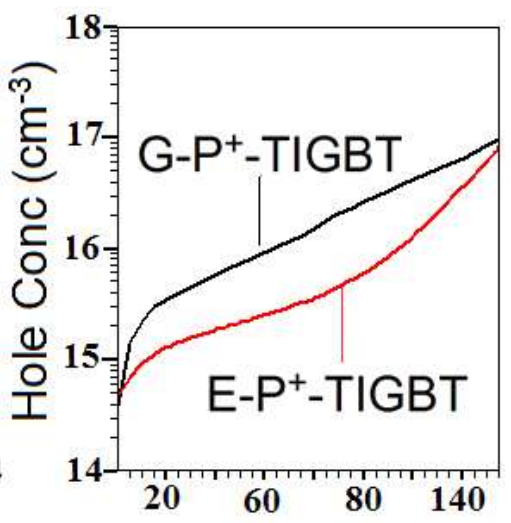

(b)

Fig. 8 (a) The tradeoff curves of the two structures (b) hole concentration distribution at $\mathrm{X}=1.8 \mu \mathrm{m}$ for E-P ${ }^{+}-$TIGBT (point B) and $\mathrm{X}=0.0 \mu \mathrm{m}$ for $\mathrm{G}-\mathrm{P}^{+}-\mathrm{TIGBT}$ (point A) 


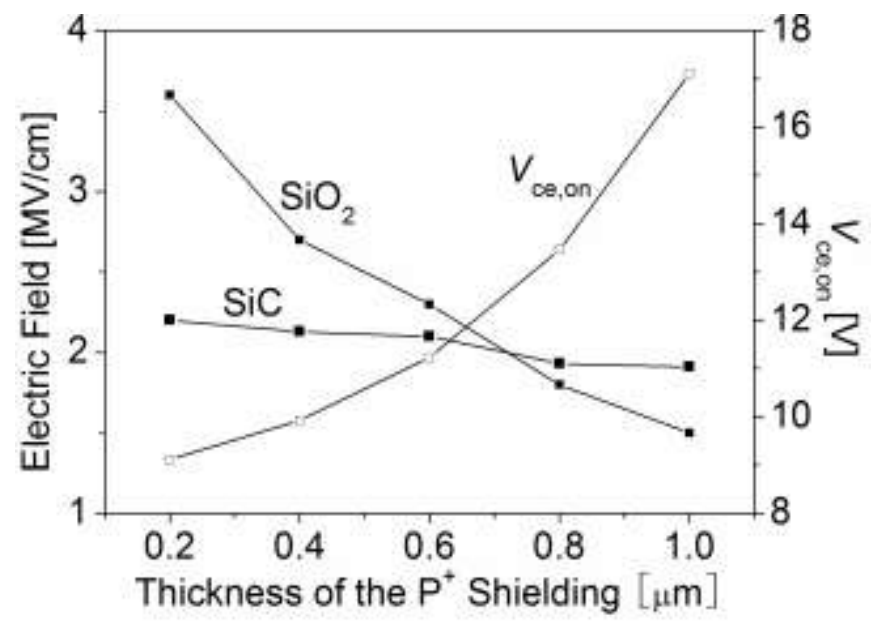

Fig. 9 The effect of the thickness of the $\mathrm{P}^{+}$shielding region on the electric field ( $@ V_{\mathrm{ce}}=15000 \mathrm{~V}$ ) and on-state voltage drop (@ $I_{\mathrm{ce}}=100 \mathrm{~A} / \mathrm{cm}^{2}, V_{\mathrm{ge}}=20 \mathrm{~V}$ ) 


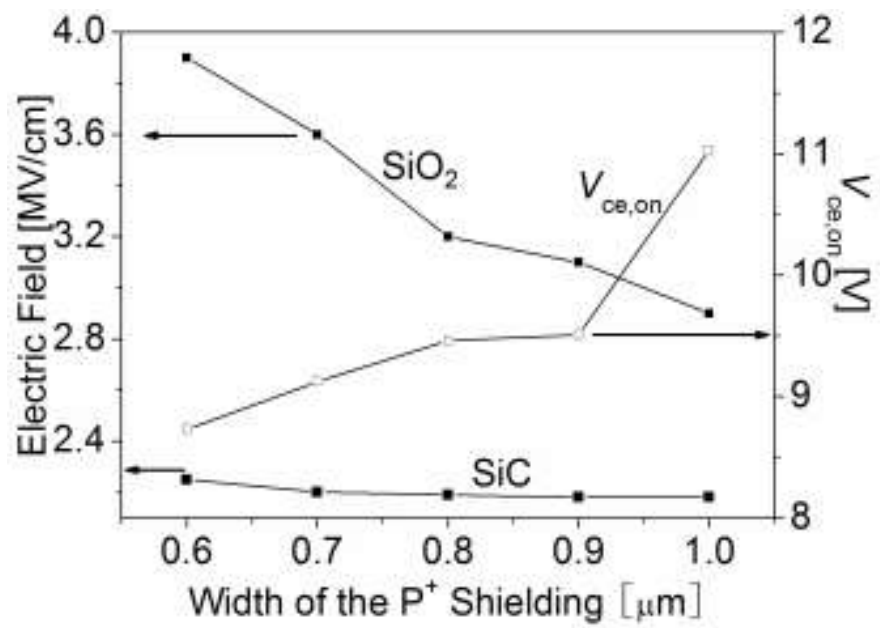

Fig. 10 The effect of the width of the $\mathrm{P}^{+}$shielding region on the electric field (@ $V_{\mathrm{ce}}=15000 \mathrm{~V}$ ) and on-state voltage drop ( $@ I_{\mathrm{ce}}=100 \mathrm{~A} / \mathrm{cm}^{2}, V_{\mathrm{ge}}=20 \mathrm{~V}$ ) 
emitter

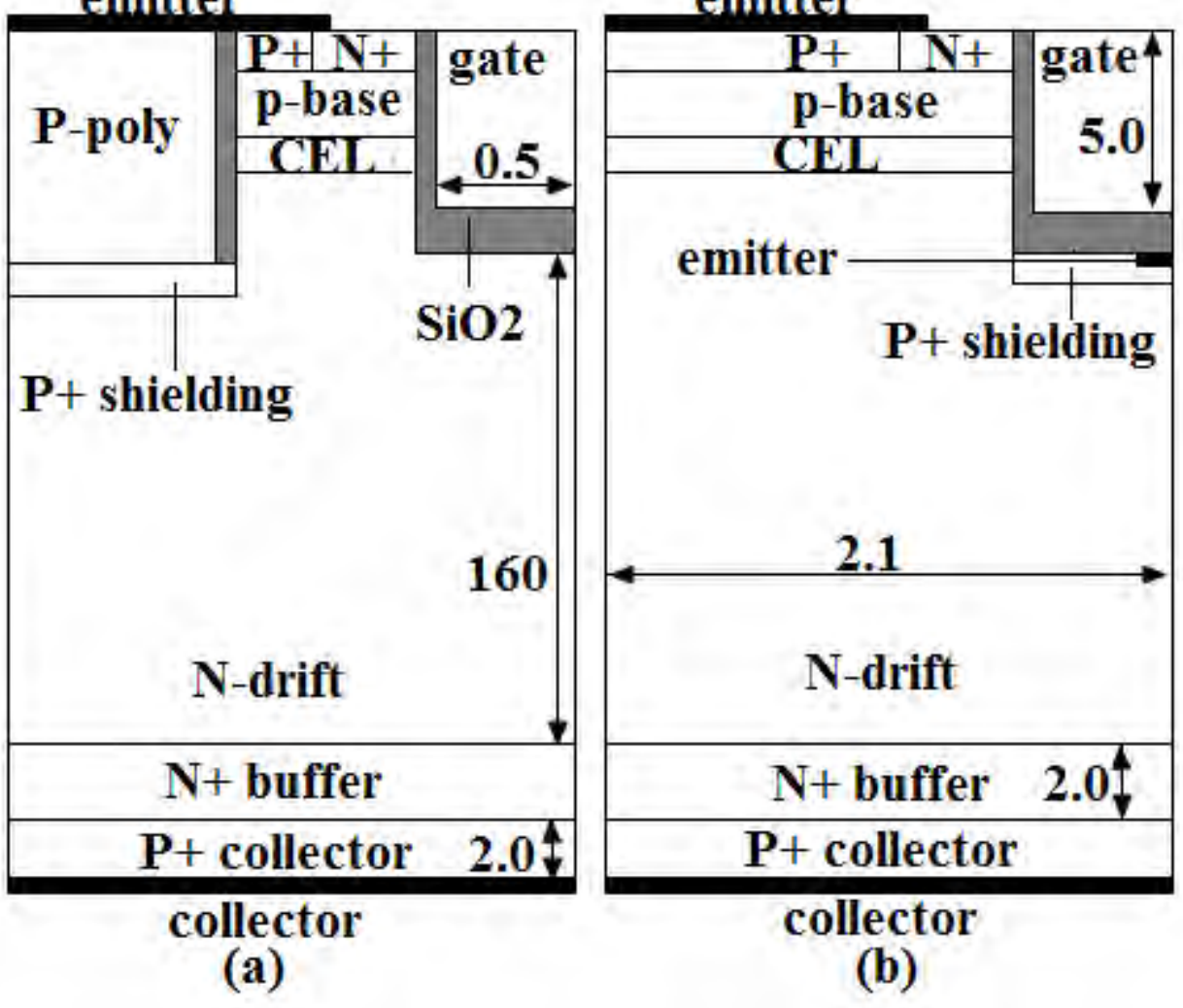


TABLE I

Physical parameters for the simulations

\begin{tabular}{|c|c|}
\hline Parameter & Value \\
\hline Concentration of $\mathrm{P}^{+}$region & $1.0 \times 10^{20} \mathrm{~cm}^{-3}$ \\
\hline Thickness of $\mathrm{P}^{+}$region & $0.5 \mu \mathrm{m}$ \\
\hline Concentration of $\mathrm{N}^{+}$region & $1.0 \times 10^{20} \mathrm{~cm}^{-3}$ \\
\hline Depth of P-poly & $5.0 \mu \mathrm{m}$ \\
\hline Concentration of P-poly & $1.0 \times 10^{19} \mathrm{~cm}^{-3}$ \\
\hline Concentration of $\mathrm{N}$-drift & $4.5 \times 10^{14} \mathrm{~cm}^{-3}$ \\
\hline Concentration of $\mathrm{N}^{+}$buffer & $5.0 \times 10^{16} \mathrm{~cm}^{-3}$ \\
\hline Concentration of $\mathrm{P}^{+}$collector & $1.0 \times 10^{19} \mathrm{~cm}^{-3}$ \\
\hline Concentration of CSL & $1.0 \times 10^{16} \mathrm{~cm}^{-3}$ \\
\hline Thickness of CSL & $0.5 \mu \mathrm{m}$ \\
\hline Thickness of $\mathrm{P}^{+}$shielding in E-P ${ }^{+}-\mathrm{TIGBT}\left(\mathrm{T}_{\mathrm{P}+}\right)$ & $0.2 \mu \mathrm{m}$ \\
\hline Concentration of $\mathrm{P}^{+}$shielding in E-P $\mathrm{P}^{+}$-TIGBT $\left(\mathrm{N}_{\mathrm{P}_{+}}\right)$ & $1.0 \times 10^{18} \mathrm{~cm}^{-3}$ \\
\hline Width of $\mathrm{P}^{+}$shielding in in $\mathrm{E}^{-\mathrm{P}^{+}-\mathrm{TIGBT}}\left(\mathrm{W}_{\mathrm{P}+}\right)$ & $0.7 \mu \mathrm{m}$ \\
\hline Concentration of $\mathrm{P}^{+}$shielding in G-P ${ }^{+}$-TIGBT & $1.0 \times 10^{19} \mathrm{~cm}^{-3}$ \\
\hline Thickness of $\mathrm{P}^{+}$shielding in G-P $\mathrm{P}^{+}$-TIGBT & $0.2 \mu \mathrm{m}$ \\
\hline Width of $\mathrm{P}^{+}$shielding in $\mathrm{G}^{-\mathrm{P}^{+}-\mathrm{TIGBT}}$ & $0.6 \mu \mathrm{m}$ \\
\hline
\end{tabular}


TABLE II

Material parameters of $4 \mathrm{H}-\mathrm{SiC}$

\begin{tabular}{|c|c|c|}
\hline Material Parameters & Value & Meaning \\
\hline $\operatorname{Eg} 300$ & $3.26 \mathrm{eV}$ & $\begin{array}{l}\text { the value of band-gap of the } \\
\text { material at } 300 \mathrm{~K}\end{array}$ \\
\hline Permittivity & 9.66 & $\begin{array}{l}\text { dielectric permittivity of the } \\
\text { material }\end{array}$ \\
\hline $\mathrm{E}_{\mathrm{db}}$ & $0.1 \mathrm{eV}$ & donor energy level \\
\hline $\mathrm{G}_{\mathrm{cb}}$ & 2 & $\begin{array}{l}\text { the conduction-band } \\
\text { degeneracy factor }\end{array}$ \\
\hline $\mathrm{E}_{\mathrm{ab}}$ & $0.2 \mathrm{eV}$ & acceptor energy level \\
\hline $\mathrm{G}_{\mathrm{vb}}$ & 4 & $\begin{array}{l}\text { the valence-band degeneracy } \\
\text { factor }\end{array}$ \\
\hline Taun0 & $1 \mu \mathrm{s}$ & SRH lifetime for electrons \\
\hline Taup0 & $1 \mu \mathrm{s}$ & SRH lifetime for holes \\
\hline Nsrhn & $3 \times 10^{17} \mathrm{~cm}^{-3}$ & $\begin{array}{l}\text { the SRH concentration } \\
\text { parameter for electron }\end{array}$ \\
\hline Nsrhp & $3 \times 10^{17} \mathrm{~cm}^{-3}$ & $\begin{array}{l}\text { the SRH concentration } \\
\text { parameter for holes }\end{array}$ \\
\hline
\end{tabular}

